\title{
ESPAÇOS LITERÁRIOS DE DESTRUIÇÃO
}

\author{
Karen Cristina Garbo \\ Mestranda em Crítica Literária pela Universidade Federal do Rio Grande do Sul (UFRGS) \\ garbo.k@hotmail.com
}

\section{RESUMO}

Parte-se do conceito de destruição para se pensar a literatura como espaço de novas significações, dentro da ótica deleuziana. A destruição emerge como um novo conceito dentro do contexto do capitalismo tardio, em que o colapso da história, em consequência do tempo acelerado, provoca novas interpretações espaciais, sobretudo na literatura. Com base neste contexto filosófico, propõe-se a análise de três obras literárias que trazem o exercício da destruição enquanto potência da literatura: Os 120 dias de Sodoma, de Marquês de Sade; "A colônia penal", de Franz Kafka e Os anéis de Saturno, de W. G. Sebald.

Palavras-chave: Literatura; destruição; espaço; conceito.

\section{ABSTRACT}

Regarding the concept of destruction, we may think of literature as a space of new meanings, inside the deleuzian view. Thus, destruction emerges as a new concept within the context of the late capitalism, in which the collapse of history as a consequence of accelerated time provokes new spatial interpretations, especially in literature. Considering this philosophical context, this study proposes the analysis of three literary works that reveal the exercise of destruction as a powerful force in literature: The 120 Days of Sodom, by Marquis de Sade, the short story "In the Penal Colony", by Franz Kafka and The Rings of Saturn, by W. G. Sebald.

Key-words: Literature; destruction; space; concept. 
Talvez uma das abordagens mais ricas que temos à disposição sobre a formação de conceitos esteja na obra de Gilles Deleuze e Felix Guattari. No livro O que é filosofia, os autores franceses nos oferecem a possibilidade de pensar os conceitos numa perspectiva dinâmica e singularizada. Se a filosofia é a criação de conceitos, essa criação não é estanque, não se dá por acumulação. Os autores assim pensam os conceitos:

[...] uma multiplicidade, uma superfície ou um volume absolutos, autoreferentes [sic], compostos de um certo número de variações intensivas inseparáveis segundo uma ordem de vizinhança, e percorridos por um ponto em estado de sobrevoo. O conceito é o contorno, a configuração, a constelação de um acontecimento por vir. Os conceitos, neste sentido, pertencem de pleno direito à filosofia, porque é ela que os cria, e não cessa de criá-los (DELEUZE; GUATTARI, 1966, p. 46).

Assim, os conceitos, mais do que definições posteriores aos acontecimentos, são o próprio acontecimento, e fazem parte do plano da imanência. O plano de imanência é a superfície onde os conceitos se integram, tornam-se conexões com o fazer filosófico. Isso é de primeira importância para a literatura, pois é na literatura que o plano de imanência ganha uma das suas encarnações mais potentes. Num horizonte de narrativas fragmentadas, em que as conexões virtuais e a comunicação acelerada derrubaram as grandes narrativas ou a expectativa de um futuro restaurador', a literatura é um espaço, mais do que nunca, de experimentação pura, de atenção para realidades alternativas, encarnadas na emergência das vozes minoritárias, e de lapidação de conceitos novos para entender o nosso tempo. E novo aqui se diz não no sentido do capitalismo simbólico, que necessita de roupagens frescas para estímulo do consumo intelectual, e sim de uma nova possibilidade interpretativa, uma possibilidade literária consciente da imanência que nos cerca. Desse modo, trago para a discussão literária o conceito de destruição. Os casos a que o 
relaciono são meros exemplos, podendo ser aplicado a outros, mais recentes.

Se no rizoma se abrem as potências infinitas do existir, esse é um ato destrutivo. Porque toda criação é também destruição. Mas antes de desenvolver o conceito de destruição, é preciso passar pelo conceito de espaço.

Sendo a literatura uma ferramenta com potência de deslocamentos, o exercício pleno do esquizo em estado de gozo, é por meio da propagação de imagens que se criam lugares únicos na mente do leitor, visitados pela leitura e revisitados pela lembrança. Espaços em que se movem as narrativas do sonho e do devaneio. Esses espaços criados no texto, ricos de imagem e som, fazem parte do percurso literário, e criam com outros leitores um lugar compartilhado, um encontro de cúmplices. "Escrever nada tem a ver com significar, mas com agrimensar, cartografar, mesmo que sejam regiões ainda por vir" (DELEUZE; GUATARRI, 1995, p. 11). Regiões compartilhadas pelo sonho e pela experiência.

Nesse sentido, esse artigo é também a repetição e processamento de algo já dito, nada de novo é realmente criado e toda afirmação literária relevante reverbera em outras, de maior ou menor alcance. Como a lenda de Eco, o fazer literário se apropria de uma voz primordial, ou, para nos atermos às questões trabalhadas por Nietszche a respeito da causalidade, o eco pode ser anterior à voz. O fazer literário posterior pode ser anterior ao acontecimento em quem se inspira:

De tal modo que o hábito nunca forma uma verdadeira repetição: ora é a ação que muda e se aperfeiçoa, permanecendo constante uma intenção; ora a ação permanece igual em meio a intenções e contextos diferentes. Ainda aí, se a repetição é possível, ela só aparece entre duas generalidades, sob estas duas generalidades, a de aperfeiçoamento e a de integração, pronta para revertê-las, dando testemunho de outra potência (DELEUZE, 2018, p. 14). 
Uma concepção espacial das narrativas já foi abordada por Gaston Bachelard, em que o autor argumenta que os espaços em que circulamos são espaços de narrativas e lembranças, e é por causa desses espaços evocados que criamos a noção de tempo:

Mas quando se trata de um devaneio poético, de um devaneio que frui não só de si próprio, mas que prepara para outras almas deleites poéticos, sabe-se que não se está mais diante das sonolências. $O$ espírito pode chegar a um estado de calma, mas no devaneio poético a alma está de guarda, sem tensão, descansada e ativa (BACHELARD, 1998, p. 187).

A discussão sobre a submissão do tempo ao espaço não é nova, e no campo da física, desde Albert Einstein a discussão sobre o tempo só poder existir como um espaço percorrido, ela criou a possibilidade para a mesma discussão em outras áreas do saber, como a filosofia. Estou ciente da discussão de Henri Bergson acerca da distinção entre tempo e espaço. Para ele, numa explicação de Deleuze:

Ela significa que minha própria duração, tal como eu a vivo, por exemplo, na impaciência das minhas esperas, serve de revelador para outras durações que pulsam com outros ritmos, que diferem por natureza da minha. E a duração é sempre o lugar e o meio das diferenças de natureza, sendo inclusive o conjunto e a multiplicidade delas, de modo que só há diferenças de natureza na duração - ao passo que o espaço é tão somente o lugar, o meio, o conjunto das diferenças de grau (DELEUZE, 1999, p. 23).

Ao pensar numa lógica excludente, talvez se esteja perdendo tempo, ou espaço, de acordo com a perspectiva. De modo que está será uma abordagem através dos espaços, sem ponderar muito nesse momento se essa abordagem espacial precisa ser excludente do tempo: 
Aqui o espaço é tudo, porque o tempo não mais anima a memória. A memória - coisa estranha! - não registra a duração concreta, a duração no sentido bergsoniano. Não se podem reviver as durações abolidas. Só se pode pensá-las na linha de um tempo abstrato privado de toda densidade. É pelo espaço, é no espaço que encontramos os belos fósseis de uma duração concretizados em longos estágios. O inconsciente estagia (BACHELARD, 1998, p. 203).

Pensando sobre a literatura como espaço possível de rizoma, como um dividir da existência rizoma com o mundo, em que se basearia o corte de um espaço específico para análise? De certo modo, toda a história é feita de espaço. O livro também pode ser espaço de destruição, de criação reversa. Não poderíamos pensar mesmo na dinâmica corte/fluxo/corte/fluxo como uma dinâmica da destruição? Se sob a ótica do corpo sem órgãos, a literatura emerge como um ato disruptivo, gostaria de pensá-la também como uma poética das destruições. Para o fazimento do livro, se gasta a energia do autor, o ato voluntário de leitura, as árvores que farão o papel, etc. Gasta-se, sobretudo, a variedade de interpretações no ato de leitura unívoco. Toda leitura é primordialmente unívoca. Depois de uma primeira interpretação, podem se abrir as possibilidades para outras, mas o ato cognitivo demanda que sejam interpretações sobrepostas, não simultâneas. Um bom exemplo de uma literatura das destruições está em Marquês de Sade. Nele não restam as sutilezas das narrativas correntes. Sua narrativa serve para levar o ser humano às suas últimas consequências, para atingir estados agônicos de redenção:

Descobriu-se nesse dia que o tempo emprestara sua aprovação às empresas infames de nossos libertinos, e os removera para uma distância maior da probabilidade de serem observados por olhos mortais; caíra um imenso manto de neve, encheu o vale circundante, parecendo proibir até os animais selvagens de se aproximarem do esconderijo de nossos safados; de todos os seres humanos, não existia um que se atrevesse a esperar atingir o lugar onde se encontravam. Ah, não é facilmente que se imagina a voluptuosidade, a lascívia, a alegria feroz conseguida por 
tais certezas, ou o que significa quando podemos dizer a nós próprios: "Estou sozinho aqui, estou no fim do mundo, afastado de todos os olhares, aqui ninguém me pode alcançar, não há criatura que possa vir onde estou: não há limites, por isso, não há barreiras; sou livre". Portanto, quando se está assim colocado, os desejos surgem com uma impetuosidade que não conhece limites, nada os detém, e a impunidade que os eletrifica aumenta da maneira mais deliciosa toda a sua embriaguez (SADE, 2006, p. 140).

Os intentos dos quatro nobres que levam para um castelo retirado dúzias de homens e mulheres para serem violados sexualmente e frequentemente torturados é o teste de limite de Sade em todas as possibilidades. A respeito do sadismo, Deleuze faz uma consideração importante, quando diz que Sade é um entusiasta institucional. A instituição, que atravessa as intenções da lei, é a expressão suprema do sadismo, pois, diferente da ética dos contratos, tônica do masoquismo em Sacher-Masoch, a instituição transcende as vontades, seus membros são por ela atravessados. A instituição tem uma orientação de permanência através do exercício do poder. Essa intenção é a devassidão sádica. Vemos, portanto, um símbolo destrutivo encarnado em símbolo de ordem e permanência:

\footnotetext{
Mas mais característica ainda é a diferença do contrato e da instituição com relação àquilo que se chama uma lei: o contrato é realmente gerador de uma lei, mesmo que essa lei venha ultrapassar e desmentir as condições que lhe dão nascimento; pelo contrário, a instituição se apresenta como sendo de uma ordem muito diferente da lei, tornando as leis inúteis, e substituindo o sistema de direitos e deveres por um modelo dinâmico de ação, de poder e de potência (DELEUZE, 1983, p. 85).
}

O ato literário de Sade é um desejo de onipotência, em que o autor desejava desaparecer depois de sua morte, desejo expresso na carta que deixou com as instruções para o seu enterro, uma cova sem demarcação, pois sabia que sua obra o superava: 
Sade ultrapassou todos os limites com sua imaginação: utilizou os privilégios que o regime feudal dava a seus senhores e criou uma espécie de homem soberano que, onipotente e impunemente, podia dominar o mundo. Solitária soberania reduzida à negação do valor do outro, de qualquer tipo de ternura, piedade, gratidão e amor; negação das leis, de toda espécie de freio, até mesmo da capacidade de prazer, pois os grandes libertinos são aqueles que neles próprios aniquilaram qualquer capacidade de prazer e de volúpia em nome de um crime de perpétuo efeito, capaz de arrastar para uma corrupção geral, uma perturbação para além da própria vida (HEUSER, 2016, p. 75).

A literatura como um espaço privilegiado para a criação de singularidades talvez resida na sua condição de contradição inerente. Esse processo de escavar a si próprio, na eliminação ou na valorização das contradições do ato de escrita, já foi abordado por Jacques Derrida. O autor explica que, de acordo com filósofos como Platão, Kant e Heiddeger, a escrita é sempre uma ferramenta incompleta na sua função de dizer. Essa incompletude refere-se ao padrão platônico em que a escrita é uma manifestação secundária no plano ideal de enunciação, padrão seguido pelos filósofos até a quebra suscitada com Nietzsche. A escrita é apenas uma aproximação do discurso, uma possibilidade errática de comunicação entre o emissor e o emissário: "escrever, segundo essa perspectiva, é o exterior, o físico, o não-transcendente, e a ameaça colocada pela escrita é que as operações do que deveria ser meramente um meio de expressão afetem ou infectem o sentido que deveria representar" (CULLER, 1997, p. 105).

Mas é justamente nesse desafio que se baseia a potência máxima da literatura. Justamente porque pode dizer tudo, porque pode criar as maiores ambiguidades e porque é muito difícil falar de um fato literário contestável. Novamente, é justamente no ponto fraco do discurso que se mostra também a sua força. O livro se desprende de sua representação. 
É a mesma coisa quanto ao livro e ao mundo: o livro não é a imagem do mundo segundo uma crença enraizada. Ele faz rizoma com o mundo, há evolução a-paralela do livro e do mundo, o livro assegura a desterritorialização do mundo, mas o mundo opera uma reterritorialização do livro, que se desterritorializa por sua vez em si mesmo no mundo (se ele é disto capaz e se ele pode) (DELEUZE; GUATTARI, 1995, p. 19).

E se é sempre pelo desejo que o rizoma se move ou se reproduz, é necessário pensar em que colaboram os desejos numa interpretação espacial, no que o desejo contribui para criar a aura nebulosa do ato de leitura. Descentrada, a literatura em questão só promove uma identificação fugidia, já que parece, ao sobrepor tantas contradições, se desdizer constantemente. De modo que, embora muito pessoal, é uma literatura também estranhamente fria.

É a sensação provocada por W. G. Sebald, que parece infectar com um lastro da devastação os objetos para o qual seu texto se inclina. No livro Os anéis de Saturno, acompanhamos um narrador que pode ser ou não o autor, percorrendo diversas cidades da Inglaterra. Nas praias enevoadas do norte, nos antigos palácios de aristocratas transformados em pontos de turismo, nas cidades em declínio econômico, nos relatos que the contam às pessoas que conheceu. Em tudo fica uma sensação da fugacidade:

Contra o ópio do tempo que passa, não há antídoto. O sol de inverno mostra a rapidez com que a luz se extingue na cinza, a rapidez com que nos envolve a noite. Hora após hora é incluída na soma. Até mesmo o tempo envelhece. Pirâmides, arcos do triunfo e obeliscos são pilares de gelo que derretem. Nem mesmo aqueles que encontraram um lugar entre as constelações celestes foram capazes de perpetuar a fama. Nimrod perdeu-se em Órion, Osíris no Cão Maior. As grandes famílias não duram nem a vida de três carvalhos. Justapor o próprio nome a uma obra qualquer não garante a ninguém o direito de ser lembrado, pois quem sabe se justamente os melhores não desapareceram sem deixar rastros? (SEBALD, 2010, p. 33). 
Sebald não fala a partir de uma narração ficcional, e tampouco a partir de um relato. Seu texto é um entremeio, assim como é de entremeio que os espaços de hoje se fazem. Essa nova situação dos espaços, refletida no texto sebaldiano, está também escrita no livro de Guilherme Wisnik, Dentro do Nevoeiro. O autor aborda a nebulosidade do mundo pós-moderno, em que o capitalismo tardio dissolveu a sensação de permanência das coisas, e deixou no lugar a sensação de uma transitoriedade, em que foram borradas as fronteiras entre realidade e ficção:

Trata-se da invenção de um mundo inteiramente artificial, denso e heterogêneo, que se materializa no arranha-céu: uma cidade vertical sem coesão interna, cujos elementos de conexão - o elevador e a escada rolante - não são espacialmente articulantes. (...) primeiro na forma de grandes lojas de departamento e shopping centers, e depois nos complexos multifuncionais que agregam centros empresariais, culturais, de convenções, hotéis, setores comerciais, serviços variados, estacionamentos e terminais intermodais de transporte. Construções cuja escala incomensurável problematiza a antiga distinção entre edifício e cidade, invalidando qualquer pretensão contextualista a um diálogo urbano (WISNIK, 2018, p. 193).

Apesar da hipervisibilidade digital e do encurtamento das distâncias do mundo com a velocidade do transporte, sentimos o espaço como uma manifestação opaca, como uma estrutura grande demais para ser apreendida, efeito perfeitamente reproduzido pelo texto de Sebald. Se a destruição que ele narra em seu texto é a que ele percebe naquilo que descreve, sua forma também se apropria dessa intenção destrutiva e nos provoca na leitura uma sensação de abandono e de desânimo estranhamente familiares:

É necessário viver na transitoriedade de todas as condições. A arquitetura é realizada com materiais transitórios, para espaços transitórios, num mundo que desfez as fronteiras entre trabalho e lazer, ou entre o escri- 
tório e a vida doméstica, congelando-se numa espécie de sexta feira informal e interminável (WISNIK, 2018, p. 113).

Há também em sua crítica e seu lamento o fim da temporalidade, ou melhor, de um estreitamento das noções de passado e futuro, no sentido mais amplo, das sociedades contemporâneas. Aqui, a estranheza temporal que o narrador evoca relaciona-se diretamente com sua melancolia. Frente ao tempo cada vez mais imperativo da produção, o espaço para a construção da identidade é cada vez mais estreito frente à ampliação do presente, único momento importante para a produção capitalista. Espaço estreito ou espaço neutro.

O trabalho de Sebald também é o de um historiador dos limites. Na degradação das cidades, nas pinturas que sofrem com a agência do tempo, na própria constatação de seu corpo cansado, em tudo paira uma sensação embotada de desligamento, de uma destruição resignada de si mesmo em consonância com a destruição frenética que o cerca. Mesmo quando o narrador percorre praias e paisagens naturais, permanece em sua visão a imagem obsessiva da ruína. Talvez não haja nada mais humano do que a ruína, e nem forma mais agônica que a destruição que permanece enquanto substância atrofiada.

Não se poderia pensar nada diferente numa existência que depende totalmente da combustão de uma estrela, e cuja extinção, que já tem data marcada para acontecer, condiciona também o fim da vida na terra. O inconsciente coletivo está a par dessas condições, e queima-se voluntariamente, num mundo movido por um princípio de "destruição alegre", pensando na filosofia do martelo de Zaratustra, numa poética das cinzas. E nesse movimento de destruição, o narrador engata entre o seu percurso o relato das maiores barbáries cometidas na humanidade, desde o Congo Belga, passando pelos genocídios na Bósnia e a Segunda Guerra Mundial: 
A população feminina de Kozara foi levada para a Alemanha e, lá, a maioria dela foi transformada em sucata no sistema de trabalho escravo que se estendia sobre todo território do Reich. Das crianças deixadas para trás, vinte e três mil em número, a milícia matou a metade ali mesmo, enquanto a outra metade foi recolhida em diversos pontos de aglomeração para ser enviada à Croácia, e dessas, por sua vez, não foram poucas as que morreram de tifo, exaustão e medo, antes mesmo de chegar à capital croata. Daquelas que ainda se achavam vivas, muitas estavam tão famintas que comeram as cartelas de papelão com seus dados pessoais que usavam ao redor do pescoço, e assim, no desespero extremo, extinguiram seu próprio nome (SEBALD, 2010, p. 105).

Sob o signo de Saturno, uma melancolia crescente se apodera do leitor, que partiIha no espaço do texto o absurdo da vida e dos empreendimentos humanos. A obra de Sebald poderia ser classificada como uma Literatura Menor. Por sua aproximação intelectual e artística com autores periféricos da Áustria e pela busca de uma literatura desfocada, no estilo bricoleur, seu estilo agrega as características de um percurso criativo em que as margens estão sempre difusas:

Seja em suas leituras, seja em suas pesquisas ou em seus ensaios, Sebald sempre voltou a procurar a companhia de autores "menores" para decifrar as mensagens sutis dos seus textos e para tornar visível aquilo que havia sido deixado de lado, por meio de uma leitura empática que, talvez, poderíamos chamar de um início de uma área de estudos literários "menores" (SCHÜTTE, 2016, p. 26).

Estar em sua própria língua como estrangeiro. É assim que Deleuze e Guattari definem o fazer literário de Kafka, um dobrar das margens da literatura que envolve o estranhamento, a depuração e a ressonância. A produção de Kafka, analisada no livro Por uma literatura menor, é exposta como uma subversão, como uma revolta "infantil" (infantil aqui não contém um tom negativo) contra qualquer utilidade, especialmente a da 
ordem social. "Uma literatura menor não é a de uma língua menor, mas antes uma que a minoria faz em uma língua maior. (...) a primeira característica é que a língua aí é modificada por um forte coeficiente de desterritorialização" (DELEUZE; GUATTARI, 1977, p. 25).

Talvez um dos melhores exemplos de uma literatura da destruição em Kafka esteja em "Na Colônia Penal". O funcionamento da máquina é também o funcionamento do próprio texto, em que as agulhas da máquina escrevem nas costas do condenado a sua sentença.

Com o cenho franzido o explorador observou o rastelo. As informações sobre o procedimento judicial não o tinham deixado satisfeito. Contudo, teve de admitir a si mesmo que aqui se tratava de uma colônia penal, que aqui eram necessárias medidas excepcionais e que se precisava proceder até o limite de modo militar (KAFKA, 2011, p. 46).

Perceber a necessidade dessas medidas excepcionais é também o próprio estranhamento do personagem em relação a uma verdade mais profunda e desconfortável. 0 condenado é o indivíduo civilizado, acossado pela opressão da ordem, da burocracia, do progresso utilitarista. Em seus mecanismos, a ordem gera a destruição das subjetividades. E dentro dessa lógica, a justiça não passa de uma arbitrariedade dentro das vastas possibilidades da lei.

Se a máquina da colônia penal, enquanto representante da lei, aparece como arcaica e ultrapassada, não é de modo algum, como frequentemente se disse, porque aí haveria uma nova lei mais moderna, mas porque a forma da lei em geral é inseparável de uma máquina abstrata autodestrutiva e que não pode desenvolver-se concretamente (DELEUZE; GUATTARI, 1977, p. 71). 
Poderíamos falar em imagens sobrepostas? Assim como a memória, uma primeira leitura, como um rizoma autêntico, está prenhe de possibilidades. As interpretações, análises do texto, como um decalque, um elemento centralizado que se bota como árvore ou como estrutura. Ao gosto de Deleuze e Guattari, o rizoma é rápido como o esplendor de uma ideia curta: "escreve-se com a memória curta, logo, com ideias curtas, mesmo que se leia e releia com a longa memória dos longos conceitos. A memória curta compreende o esquecimento como processo; ela não se confunde com o instante, mas com o rizoma coletivo, temporal e nervoso" (DELEUZE; GUATTARI; 1995, p. 25). Talvez isso seja trabaIhado ao máximo no texto de Kafka. A obra de Kafka, e, para o exemplo que trago aqui, a máquina penal, é uma sucessão de ideias curtas. Apesar da metódica apresentação do oficial, de sua paixão zelosa, a máquina salta no texto como um organismo vivo, como se não estivesse apenas observando os dois homens que falam dela na sua presença, mas como se estivesse agindo na própria forma do texto, sendo também parte de quem a contempla:

O artista é o senhor dos objetos; integra na sua arte objetos partidos, queimados, estragados, para submetê-los ao regime das máquinas desejantes, nas quais o desarranjo faz parte do próprio funcionamento; ele apresenta máquinas paranoicas, miraculantes, celibatárias como outras tantas máquinas técnicas, pronto a minar as máquinas técnicas com máquinas desejantes. Mais ainda: a própria obra de arte é uma máquina desejante (DELEUZE; GUATTARI, 2010, p. 49).

Diversas interpretações já foram feitas a respeito da colônia penal. Uma das mais populares é a da representação do processo colonizador. O espírito arrivista do imperialista levado a seus extremos parece ter encontrado a sua face mais cruel na exploração do Congo Belga, em que a extração mineral transformou-se numa gigantesca máquina de 
morte, com milhares de trabalhadores escravizados morrendo todos os dias pela aplicação dos castigos ou pela exaustação das horas ininterruptas de trabalho. O visitante ouve a explicação do procedimento com constrangimento, com repulsa até. Se para Kafka, a libertação só vem pela morte, "A Colônia Penal" serve como imagem da exploração colonial enquanto também ilustra a própria vida, em que a condição pela espera da morte é uma tortura certa, ao mesmo tempo em que insustentável.

Para repetir a pergunta feita por Guattari e Deleuze no Anti-Édipo: “qual é o corpo sem órgãos de um livro?". Talvez seja o livro texto que representa, ou ainda melhor, personifica a sua própria destruição:

Fazer vibrar sequências, abrir a palavra para intensidades interiores inauditas, em resumo, um uso intensivo assignificante da língua. Ainda do mesmo modo, não há sujeito de enunciação nem sujeito de enunciado: não é mais sujeito de enunciado que é um cão, permanecendo sujeito (DELEUZE; GUATARRI, 1995, p. 34-35).

De modo que no corpo sem órgãos há a possibilidade pura da criação, do fazer criativo como romper de todas as dimensões. Não é uma questão de elencar os melhores meios para a materialização do corpo sem órgãos é, sobretudo, pensar no que a literatura faz pelo registro, pela possibilidade do corpo sem órgãos. Assim, podemos pensar a planície literária como um rizoma. A cada leitor um novo mapa mental, uma nova ramificação. Um novo passado de vivências que transformará o espaço a ser lido e a ser vivido. Por mais vívida e específica que seja a estrutura descrita, os espaços rizomáticos são sempre renovados para cada leitor. "O mapa é aberto, é conectável em todas as suas dimensões, desmontável, reversível, suscetível de receber modificações constantemente" (DELEUZE; GUATARRI, 1995, p. 21). 
Portanto, não se trata de representação. A representação é um falar do outro, é um ato do emissor que busca a aproximação com o outro, geralmente periférico, na busca de uma identificação ontológica. Esquema que no fundo não foge muito da lógica platônica. Deleuze e Guattari já nos alertaram sobre a armadilha da representação:

Mas, com o Édipo, essa descoberta foi logo ocultada por um novo idealismo: substituiu-se o inconsciente como fábrica por um teatro antigo; substituíram-se as unidades de produção inconsciente pela representação; substituiu-se o inconsciente produtivo por um inconsciente que podia tão somente exprimir-se (o mito, a tragédia, o sonho...) (DELEUZE; GUATTARI, 2010, p. 40).

Nesse caminho, Sade representaria a fúria dos revoltosos iletrados, Kafka a violência sofrida pelos colonizados e Sebald a depressão da multidão de anônimos da pósmodernidade. São chaves interpretativas que funcionam. Numa concepção estética da destruição, não há nada mais exemplar do que a violência. Mas a representação é apenas mais um dos redutos do rizoma. Na crítica realizada por Gayatri Spivak (2010, p.47) a uma construção discursiva do centro em direção à periferia, a autora enfatiza que é impossível falar de um Outro, porque toda construção da alteridade, especialmente no sentido centro periferia, é envolvida por uma camada ideológica inerente: “O mais claro exemplo disponível de tal violência epistêmica é o projeto remotamente orquestrado, vasto e heterogêneo de se construir o sujeito colonial como Outro. Esse projeto é também a obliteração assimétrica do rastro desse Outro em sua precária Subjetividade." Falar através de espaços abre mais possibilidades. Sai a tentação de representar e surge a possibilidade da performance. Os espaços do livro tornam-se, sem o intermédio da metáfora, espaços que falam sobre si mesmos. Com o risco de tomar novamente um caminho rizomático fechado, ou decair numa estrutura achatada, o castelo de Sade seria o espaço das perversões 
institucionais aniquiladoras frente à moral institucional e religiosa, a máquina penal de Kafka o espaço da violência tecnológica, e as paisagens de Sebald a desintegração dispersiva. Pois, se no auge da Revolução Francesa o meio de afirmação pessoal é pela violência espontânea e desregrada, e, na Primeira Guerra Mundial, a violência se converte no absurdo racional da máquina, o narrador sebaldiano percorre espaços desolados, ruínas esquecidas num mundo desencantado. Espaços são formas de reviver experiência, é no espaço que o tempo se repete enquanto acumulação. O tempo, sobreposto no espaço, é a manifestação máxima do rizoma. E é através da destruição criativa que essa operação acontece:

Tal como nossos corpos e nossos desejos, as máquinas que idealizamos têm um coração cujas brasas se extinguem lentamente. Desde o início, toda civilização humana não foi mais que uma incandescência que cresce hora a hora de intensidade, da qual ninguém sabe dizer até que grau aumentará e quando começará a minguar progressivamente. Por enquanto, nossas cidades ainda brilham, ainda se espalham os fogos ao seu redor (SEBALD, 2010, p. 172).

\section{Referências}

BACHELARD, Gaston. A poética do espaço. São Paulo: Martins Fontes, 1998.

CULLER. Jonathan. Sobre a desconstrução. Rio de Janeiro: Rosa dos Tempos, 1997.

DELEUZE, Gilles; GUATTARI, Félix. Kafka: por uma literatura menor. Rio de Janeiro: Imago, 1977.

. Mil platôs. Rio de Janeiro: 34, 1995. v. 1.

. O anti-Édipo. Rio de Janeiro: 34, 2010.

. O que é a filosofia? Rio de Janeiro: 34, 1996. 
Apresentação de Sacher-Masoch: o frio e o cruel. Rio de Janeiro: Taurus, 1983.

. Diferença e repetição. São Paulo: Paz e Terra, 2018.

. Bergsonismo. São Paulo: 34, 1999.

DERRIDA, Jacques. Essa estranha instituição chamada literatura. Uma entrevista com Jacques Derrida. Belo Horizonte: Editora da UFMG, 2014.

HARTOG, François. O tempo desorientado. Tempo e história. Como escrever a História da França? Anos 90 - Revista do Programa de Pós-Graduação em História. Porto Alegre: Universidade Federal do Rio Grande do Sul, n. 7, 1997.

HEUSER, Ester Maria Dreher. Deleuze e Masoch: a frieza da pornologia. Revista Margens Interdisciplinar, [S.I.], v. 6, n. 7, p. 67-84, maio 2016.

SCHÜTTE, Uwe. Por uma germanística "menor": W. G. Sebald e a "pequena" literatura da periferia austríaca, e de outros lugares". Cadernos Benjaminianos, [S.I.], v. 12, p. 9-27, fev. 2017.

KAFKA, Franz. Essencial. São Paulo: Penguin Companhia, 2011.

NIETZSCHE, Friedrich. Assim falou Zaratustra: Companhia das Letras, 2011.

. Crepúsculo dos ídolos. São Paulo: Companhia das Letras, 2006.

SADE, Marquês de. Os 120 dias de Sodoma ou a escola da libertinagem. São Paulo:

Iluminuras, 2006.

SEBALD, W.G. Os anéis de Saturno. São Paulo: Companhia das Letras, 2010.

SPIVAK, Gayatri Chakravorty. Pode o subalterno falar? Belo Horizonte: Editora UFMG, 2010.

WISKIK, Guilherme. Dentro do nevoeiro. São Paulo: Ubu, 2018.

Recebido em 4 de maio de 2019.

Aceite em 17 de junho de 2019.

\footnotetext{
' Para François Hartog, o futurismo do regime moderno de historicidade foi substituído por um futuro comprimido que é cada vez mais devorado pelo presente - hipertrofiado, que invade o horizonte, em uma sociedade de consumo, de imediata obsolescência de coisas e indivíduos, produzindo, consumindo, palavras e imagens (1997, p.13).
} 